\title{
Immersive Technologies in Marketing: State of the Art and a Software Architecture Proposal
}

\author{
Luis Alfaro ${ }^{1}$ \\ and Claudia Rivera ${ }^{2}$ \\ Juan Carlos Zuńiga ${ }^{4}$ \\ Alberto Barbosa Raposo ${ }^{6}$ \\ and Jorge Luna-Urquizo ${ }^{3}$ \\ and Alonso Portocarrero ${ }^{5}$ \\ Pontifícia Universidade Católica do Río do Janeiro \\ Universidad Tecnológica del Perú \\ Río do Janeiro - Brazil \\ Universidad Nacional de San Agustín \\ Arequipa - Perú
}

Arequipa - Perú

\begin{abstract}
After conducting the historical review of marketing and especially experiential marketing, which considers various types of experiences such as sensations, feelings, thoughts, actions and relationships, seeking in the consumer greater satisfaction and therefore greater effectiveness in the action of marketing, as well as establishing the state of the art of immersive technologies and their applications in marketing, the authors propose a software architecture model for hotel services, which includes the description of hardware and software elements for development and implementation. The model would make it possible to bring customers closer to experiences that are very close to reality, based on their profiles and characteristics, previously treated by a recommendation module included in the proposal, a fact that supports the decision of purchase, with a high degree of adaptation to their needs and requirements. The proposal and development of the model with attributes of originality, aims to contribute to the development and technological innovation of marketing in the hotel industry. Finally, conclusions and recommendations for future work are established.
\end{abstract}

Keywords-Marketing; experiential marketing; immersive technologies; immersive technologies in marketing

\section{INTRODUCTION}

In recent years, the hotel industry has presented a significant growth of investments, not only in physical infrastructure, but also in the provision of services, having focused on updates and innovations concerning the technologies used, such as information systems for carrying out operations and business processes and later with the revolution of the Internet and Web portals, and also for offering and advertising hotel services, which allow the realization of reservations and payment of services, as well as the execution of various business transactions. The development of technological concepts such as Internet of Things (IoT), Virtual Reality and Immersion, have led some companies in the tourism sector and the hotel industry to focus on the intensive use of these technologies to explore innovations in marketing and advertising actions, infrastructure and services offered.

Marketing and specifically experiential marketing, which includes the five types of customer experience such as sensations, feelings, thoughts, actions and relationships, according to Schmitt's proposal [1], seeks consumer experiences, greater satisfaction and therefore greater effectiveness in marketing action, which focuses on enriching experiences based on direct communication of marketing actions towards the senses of the consumer so as to influence on their decision and relationship with a product, service or brand.

These marketing approaches, added to the technological resources mentioned, as well as the possibilities of their implementation at a low cost, allow the conception and design of applications that, for example, could show landscapes and diverse hotel services among others, using metaphors through simulation, interaction and rectification, making images and other sensory stimuli connected to sensors and actuators seek the approximation to experiences that are only possible to be lived in the real world, enriching the sensory experiences notably in this way.

These concepts and technologies are considered for the formulation of the proposed model of software architecture of the authors of this work, which includes the descriptions of the hardware and software elements required for its implementation, as well as a recommendation system, which can constitute a trend in the technological development and marketing of the hotel industry, with possibilities of a direct impact on the results of business operations in the tourism sector.

The rest of this paper is organized as follows: Section II describes the fundamentals of Marketing and Experiential Marketing; Section III deals with and explores immersive technologies; Section IV explores immersive technologies applied for marketing and tourism; Section V presents the related works to the topic under study that were developed using immersive technologies; Section VI presents the proposal of software architecture for marketing systems based on immersive technologies for the tourism and hotel industry, and finally, the conclusions and future recommendations for this work are established in Section VII.

\section{MARKETING AND THE EXPERIENCES}

Marketing has been in force since the 1960's and lays its foundations in the consumer's perception of the product or service they consume. For [2], this perception passes through stages on the product or service knowledge, its acceptance or usefulness, to finally decide the purchase of the goods.

For this reason the current paradigm of marketing is to bring the consumer closer to experiences, rather than presenting the attributes of a product or service. According to [3], the lived experience also generates an increase of personal valuations on the good and with it, increase the mouth-tomouth marketing. 
In that sense, several highly successful companies, of Online or Internet nature, are implementing omnicanal strategies and entering the off-line channel, in inverse form to the regular process in the evolution of digital channels. For [4], this is because they seek to generate experiences with their clients through sensory stimulation in physical spaces and digital media.

That is why some authors [3], [5], [6] maintain that products should be offered in the market as experiences; in other words, the conditions should be created so that the use or consumption of the product is more valued than the attributes of the product itself. This implies a greater elaboration in the design of marketing strategies for the promotion and sale of these goods. From the perspective of experience, intangible products also known as services, may be easier to promote and sell, since the customer may be more sensitive to the impact they could have. The intangibility of services, or of places, as well as of the so-called experiences themselves, can allow for greater sensory stimulation, for example, through virtual reality (VR) technologies used in immersive marketing [7].

In this sense, sensory stimulation seeks to ensure that the attributes and properties of products can be perceived through human senses. According to [8], it has been possible to identify that the sense of sight influences persuasion at the moment of deciding; smell at the level of remembrance, by evoking a certain circumstance or moment; touch as a decision maker of acquisition and of greater relationship; hearing as a conditioner of experience; and taste as a complement to experience through the other senses.

Although the ideal case would be that the consumer be exposed to an experience through all senses, in practical terms it is not feasible because of the circumstances in which the product or service is offered to the consumer, the cost incurred and the technology related to the nature of the product or service offered. Whether for intangible products or services, there are several marketing management models that can be considered. However, one particular model allows to establish the characteristics of experiential marketing: the service gap model. This model proposed by Parasuraman, Valarie, Zeithalm and Berry [9], establishes the gap that exists in the perception of the consumer, when comparing the expectation versus the experience itself. This perception impacts the consumer in such a way that it influences their purchase decision and loyalty. In this model, the expectation has a prevailing role since it is the element of comparison, with which the real experience of the consumer establishes a differential that impacts on his memory and sensations. According to [9], expectation is formed from previous experience with the service, explicit and implicit communication, and word-of-mouth comments . Therefore, for [5] experiential marketing must induce customer satisfaction through proportionate emotional and functional values.

Therefore, companies should consider that the consumer today no longer chooses a product or service solely for cost-benefit, but should also include other factors such as emotions, sensations and experiences, which are experienced in the purchase of a product or consumption of a service [10]. Various companies have already begun to implement marketing strategies that provide their consumers with unique and memorable shopping experiences; according to [6], it's in this context that sensory perception plays an important role within experiential marketing.

In seeking to generate a shopping experience in the consumer, sensory marketing aims to generate memories through sensory experiences via sight, hearing, touch, taste and smell. The studies carried out by Mancillan [11], have shown that sensory impacts provoke memories linked to emotions, which make them more enduring in memory.

The role that the mind unconsciously acquires in decision making is increasingly considered relevant, making it clear that purchasing decisions have an emotional component. On the other hand, in recent years, many studies have been published on sensations, consumer behavior focused on sight, taste, touch, smell and hearing, and clearly sensory perception and sensory marketing constitute an emerging area of research [12]. As to the marketing experiences, we already have the first references with Gilmore and Pine [13] in 2002, as a result of specialization from what Hui and Bateson [14], mentioned as service experience in 1991; and Holbrook and Hirschman [15], as experience consumption.

The review of literature allows us to establish that in various investigations, the sensory experience, produced by a marketing action, begins to be related to the immersion experience, using the different senses of the consumer. The first studies found in this area were developed in 2006 [16] and 2008 [17]. In the first case, the article refers to advertising immersion based on video information, exploring mainly the visual aspect in television advertising campaigns [16]. Already in [17], a solution based on the consumer orientation of a bookstore is presented, without describing in greater detail the technologies used to make this visualization of information immersive.

Likewise, in the platform, the research carried out in [7], [18], deals with the concept of immersive marketing with the implementation of various technologies such as NFC, RFID and other types of screens, mainly to induce consumer behavior.

\section{IMMERSIVE TECHNOLOGIES}

\section{A. Virtual Reality $(R V)$}

For [19], RV is defined as: "A computer-synthesized threedimensional environment in which the plurality of human participants, with appropriate interfaces, can make contact or interact with representations of other humans from the past, present, fiction, and/or invented creatures". For Yoh [20], VR is a technology that simulates reality through software, recreating the effect, essence and sensations of a given situation that does not materialize in real events. It is currently applied in the world of entertainment, education [21], advertising, marketing, Knowledge Management, etc.

According to Psotka [22], in VR there are two types of applications, the "Immersive", where the user is inside the simulation and the "Non-immersive", where the user is outside of the simulation. Another important feature of immersive VR is "Stereoscopy", which allows users to distinguish the depth of the objects they observe, adapting to our natural way of seeing the world around us, which, according to [23] is generated by a binocular vision, creating the illusion of perceiving objects in 
three dimensions from two images that are taken from different positions, recreating human three-dimensional vision inside the simulation.

A very important element of VR is depth, which gives us an idea of the position of the objects shown, for which we use various configurations of lights, shadows, colors, slides, including even shapes [24]. For this reason Stereoscopy is a valuable alternative that improves depth perception [23]. Virtual Reality has evolved rapidly in recent decades; in its beginnings VR could only be used by scientific-military laboratories at an excessive cost of implementation. Today, due to technological progress, virtual reality equipment can be available at an affordable cost. It is precisely the unique and special features of these two devices, which are the key components considered for the design of the proposed architecture located in a virtual environment corresponding to this research.

\section{B. 2D, 3D and RV Visualization Modes}

There are different approaches to the use of 2D, 3D and RV representations in relation to the Visualization of Information [25], with the following brief description of each of them:

- $2 \mathrm{D}$ is the mode of representation that uses only two dimensions, the images are flat, it stands out for its simplicity, clarity and precision when displaying information. At present, a large part of the interfaces are designed for this type of representations. These environments stand out for their precision and clarity in interpreting information. In most of them the interaction is very traditional, using the most common interaction techniques such as: Select and Zoom, Zoom

- $\quad 3 \mathrm{D}$ is the mode in which an object is represented in a three-dimensional space, showing its width, length and height, which are mapped in a two-dimensional superficial, as is a monitor. The visual perception of three dimensions is achieved through the use of deep visual elements such as lights, shadows and perspectives, but the final appreciation is flat. These environments facilitate navigation, however, they result only from an extension of the techniques of interaction in two-dimensional environments, which resort to visual effects of lights and shadows to generate the illusion of volume, but the final representation continues to be two-dimensional.

- $\quad \mathrm{RV}$ is a technique that enables immersion in a multimodal viewing environment, which also uses stereoscopic images to improve depth perception. In this mode, the three dimensions are perceived as in the real world. Visualization environments based on virtual reality allow the immersion of the user, causing the interaction to be different. Unlike visualization techniques in 2D and 3D environments, VR techniques have not been studied in depth or standardized. An example of VR interaction techniques are: Direct manipulation, in which a virtual hand is available to interact directly with the visualization, and the metaphor of the laser beam, in which a virtual laser pointer is available, with which we can select and manipulate objects and elements.

Generally between 60 and 80 percent of the study objects to be visualized are three dimensional, but most of the visual representations implemented are in $2 \mathrm{D}$, followed by those made in 3D, and as far as those conceived in VR, these are currently very scarce [24]. The debate regarding the quality between $2 \mathrm{D}$ and $3 \mathrm{D}$ visualizations is still very extensive, but many authors agree that $2 \mathrm{D}$ representations are the most appropriate for precision and better interpretation, while 3D representations are useful for better navigation and relative positioning [26]. Fig. 1 shows an example of the three types of environments described above.

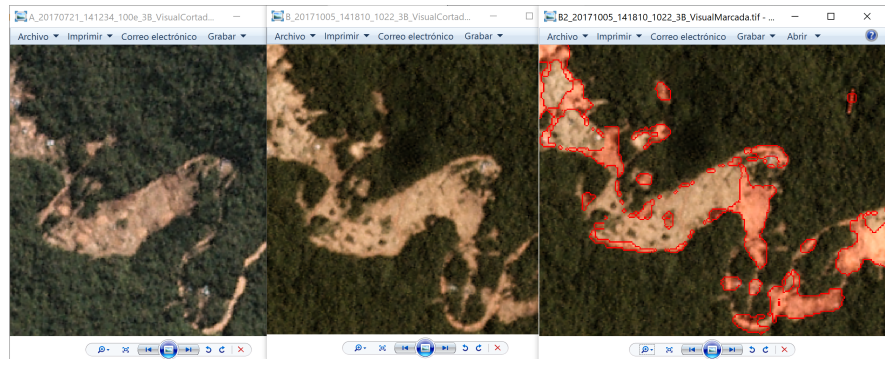

(a) Image in 2D. Source: [27]

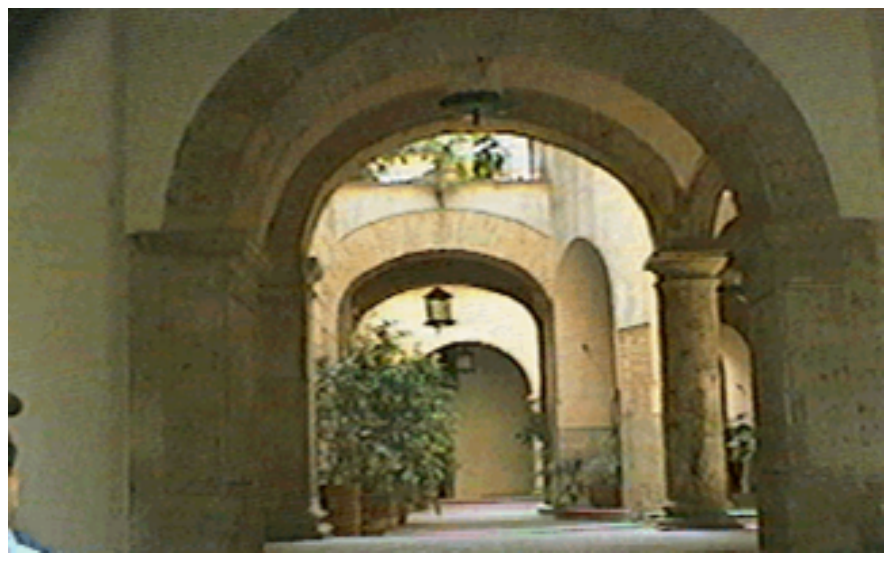

(b) Image in 3D captured by Scanner. Source: [19]

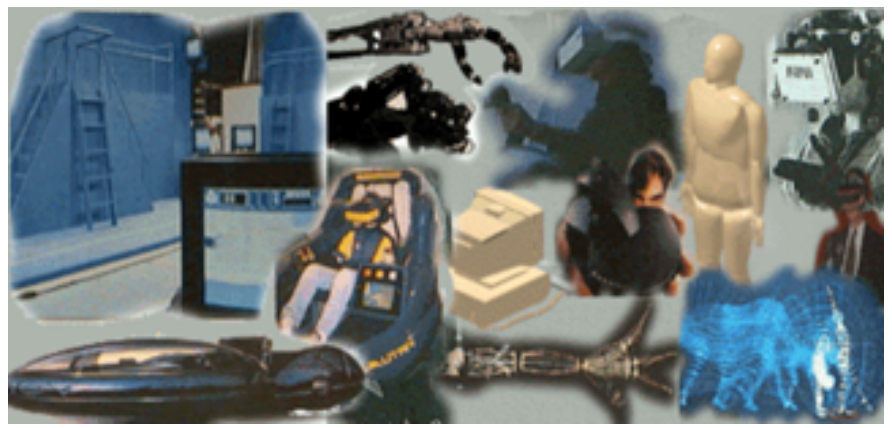

(c) Composition of Immersive Virtual Reality images. Source: [19]

Fig. 1. Modes of 2D (a), 3D (b), and RV (c) visualization

\section{Immersion}

For [22], it is a feature of Virtual Reality in which users are within the simulation. Psotka [22], maniests that the fact 
that a user is within a simulated virtual environment, has an enormous emotional factor that facilitates cognition and improves information retention, because the user feels that they are part of the software.

In addition, immersion widens the user's range of vision, even allowing displacement (which has been very useful in virtual tours) and collaboration (used for manufacturing applications) [28], [29]. For this purpose, immersion has been achieved through different configurations, for example, it could be that a single giant screen is used as well as anaglyph lenses; another configuration is a CAVE environment consisting of a room with four walls and a projector for each and another is using a headset or glasses that inside have small LCD screens, on which images are projected to the user.

In this research, use will be made of immersion based on a Virtual Reality headset, which is one of the most comfortable to use because of the tiny space taken up, in comparison with others and above all because it provides a greater sense of presence that helps memory and other cognitive processes [30]. However, one of the main drawbacks of this configuration is that it can cause dizziness in certain users.

\section{Immersive VR Devices}

Over the years different Virtual Reality devices have emerged, most of them manufactured for a specific purpose and not for common use. In this research, in relation to the proposed system architecture, the hardware configuration would be composed of the following devices: 'Oculus Rift', 'Leap Motion' and 'Oculus Go'. Fig. 2 shows the main virtual reality viewers on the market so far. Oculus Rift (Fig. 2a) is the first to include a series of improvements such as stereoscopy and a low latency in the refresh rate. Hololens (Fig. 2b) experiments with how to mix virtual reality and augmented reality, in addition to creating the first holographic processor. PlayStation VR (Fig. 2c) is created for entertainment purposes and stands out for its sophisticated design. HTC Vive (Fig. 2d) on the other hand, stands out for its good features and development platform. Gear VR (Fig. 2e) uses virtual reality with a wireless approach for which it requires a smart phone. Oculus Go (Fig. 2f) is a similar alternative to the previous one with the difference that its cost is much lower. In Table I, these visors are compared considering the main technical characteristics such as: screen resolution, refresh rate, viewing angle and price.

TABLE I. COMPARISON OF VIEWERS CONSIDERING TECHNICAL ATtributes ANd Costs. SOURCE: AdAPTED FROM [24]

\begin{tabular}{|l|c|c|c|r|}
\hline Visor & Resolution & Refresh rate & Vision angle & Price \$ \\
\hline Oculus Rift & $2160 \times 1200$ & $90 \mathrm{~Hz}$. & $110^{\circ}$ & 700.00 \\
\hline Hololens & $1920 \times 1080$ & $120 \mathrm{~Hz}$. & $110^{\circ}$ & $3,000.00$ \\
\hline PlayStation VR & $1920 \times 1080$ & $120 \mathrm{~Hz}$. & $100^{\circ}$ & 400.00 \\
\hline HTC Vive & $2160 \times 1200$ & $90 \mathrm{~Hz}$. & $110^{\circ}$ & 900.00 \\
\hline Gear VR & $2560 \times 1440$ & $60 \mathrm{~Hz}$. & $96^{\circ}$ & 100.00 \\
\hline Oculus GO & $2560 \times 1440$ & $72-60 \mathrm{~Hz}$. & $110^{\circ}$ & 169.00 \\
\hline
\end{tabular}

\section{E. Natural User Interfaces}

Natural User Interfaces (NUI) are those interfaces in which the user's interaction is natural, common and familiar to

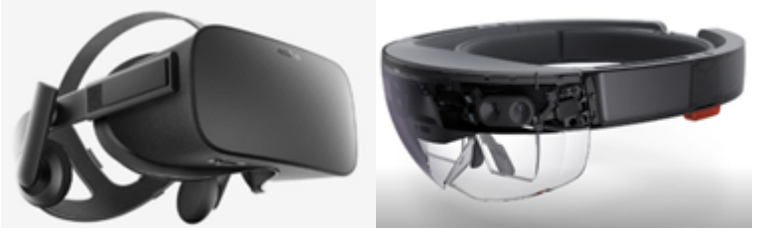

(a)

(b)

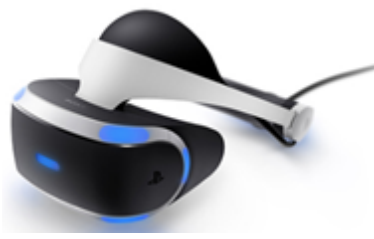

(c)

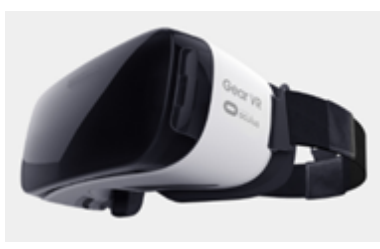

(e)

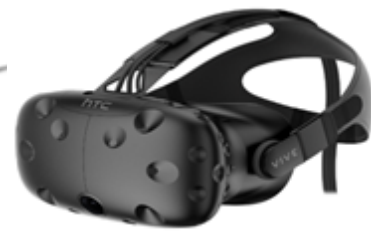

(d)

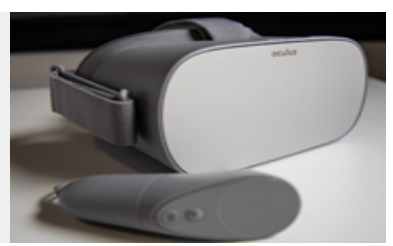

(f)
Fig. 2. Prototypes of interaction devices. Source: [31]

him [32]. That is why their design implies the use of new devices that allow this interaction, which goes beyond the use of the keyboard and mouse. These new generations of devices allow the use of software by gestures, tactile contact, corporal movement, voice communication, etc. Examples of NUI devices are the Kinect [33], [34], a device that is capable of copying the movements of the body and passing them to a virtual avatar; this device allows the user to control the application, without requiring another peripheral for the use of software, because it also allows voice recognition for the interpretation of commands.

The great advantage of using Natural Interfaces is that they are intuitive and easy to use, unlike traditional ones. For example, for non-native digital users learning to use the mouse is quite complicated, but using Kinect is relatively easy for any user. It is this ease of use that is desired in any user interface, but the NUI should not be applied to any application; for example, it would be very difficult to use a Kinect to operate a word processor.

The recent development of input peripherals and other devices is changing the way of interaction with digital screens; the mouse and keyboard, are being replaced by tactile interfaces and based on body movement [35]. These new ways of interacting are part of the evolution of interfaces, which throughout the history of computing have been evolving, changing and diversifying.

The term Natural User Interfaces - NUI, was coined by Mann [36], who explores new forms of human-computer interaction, prompting a variety of research that focuses on new fields of application. Natural User Interfaces and Virtual Reality are closely related, since the user, being part of the simulation, expects to act as if they were in the real world, 
therefore the best option to interact with the software is to use natural user interfaces.

Finally, the NUI are a revolution in the world of computing, not because they will replace the traditional interfaces already existing and which are widely used, but because they make the creation of new types of applications possible, as well as new forms of original and novel interactions that can be applied in Production Engineering, Administration, Marketing, etc.

\section{F. Natural Devices Interaction}

Fig. 3 shows the main devices needed to create natural interfaces. Microsoft Kinect 2.0 (Fig. 3a), is the first to appear for the consumer market, created for entertainment purposes for games controlled through transduction, but it was then used for more advanced applications. Nimble VR (Fig. 3b), focuses only on hand recognition.Manus VR (Fig. 3c) unlike the others , uses motion sensors built into gloves.

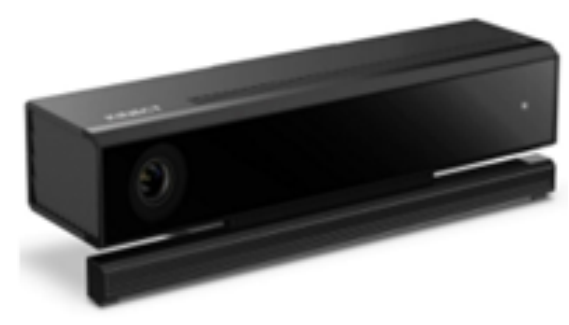

(a)

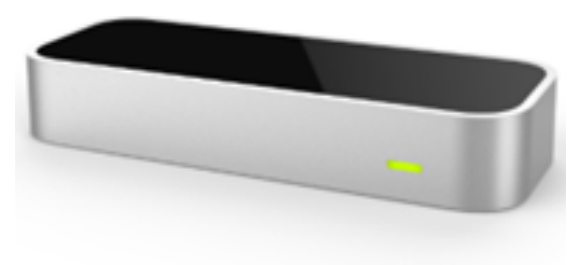

(b)

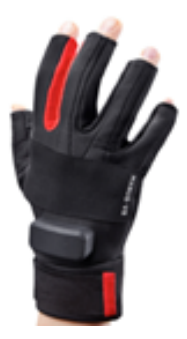

(c)

Fig. 3. Natural Devices Interaction

The historical review and the establishment of the state of the art, allow to glimpse the enormous potential of the resources and elements of immersive technologies, whose use in the marketing strategies, will allow innovative and original approaches.

\section{APPliEd TECHNOLOGIES FOR IMMERSIVE MARKETING}

As a marketing and sales strategy, Multichannel is relevant for access to customer segments that otherwise could not be reached. The delimitation of financial and non-financial factors and the criteria for evaluating the development of hotel marketing in the tourism sector is oriented towards the design of the multichannel marketing mix [37]. This multichannel marketing is based increasingly on the use of different devices and technological solutions such as social networks, which according to [38], today are a means of selling and positioning in what is called social media, a means that the tourism sector and especially the hotel sector is using.

Social media plays an important role as it allows the company to communicate and interact with its customers [39]. Techniques such as text-mining are being used, among others, for the analysis of customer opinions in the competitive hotel industry [39]. Techniques that use technical attributes of online text review and that seek to predict the level of consumer satisfaction [40], is another of the current lines of development. However, the so-called "immersive" technologies are the most promising to carry out the effective implementation of the concepts of experiential and sensory marketing.

Research in immersive technology is applied to diverse environments, including education, marketing, business, and medical care [41], y and is implemented through technologies called Virtual Reality (VR) and Augmented Reality (AR), which have greater utility and depth over immersion.

In [42], researched the effect of recent Virtual Reality technologies on consumer behavior and established guidelines for designing an environment capable of delivering a memorable, high-impact experience and attracting potential audiences and consumers, anytime, anywhere. These authors propose a VR environment design with technological characteristics of interactivity, hypertextuality, virtuality (presence of virtual elements), modality, location specificity, mobility and connectivity. The environment considers the technological characteristics of virtual reality, in terms of the capacity of virtual reality devices, which can have an effect on cognition, affectivity and behavioral manifestations.

It is in this context is that the Immersive Virtual Reality offers unique experiences in which the client or user lives an immersion that allows the perception of a reality through the different senses and, as Winn [43] maintains, there would be possibilities to expand these experiences through transduction, an experience in which the traditional interfaces between the user and the computer are changed and the user literally "dresses the computer" which makes it possible for one to live experiences, using the bodily movements that interact with the system. It is also possible to transform reality through reification, allowing beaches, oceans, swimming pools, hotel facilities, etc. to be seen from various angles and even magnified.

\section{RELATED WORKS ABOUT IMMERSIVE MARKETING SYSTEMS FOR THE TOURISM INDUSTRY}

In [44] a study of the state of the art on the application of Virtual Reality technologies in the tourism sector is carried out, where the concepts of immversive marketing begin to be explored. Among the main contributions of this research we can indicate:

- The immersion of Virtual Reality in the tourism sector determines the type of technological solution applied, 
which can be non-immersive, semi-immersive and totally immersive. The more immersive the solution, the more complex and complicated will the technological devices and the virtual content be.

- The technological devices, which for cost-benefit and immersion capacity, are mostly used in VR solutions in tourism are the HMDs - Head Mounted Displays or also called lenses or virtual reality headsets. There are high immersion HMDs that communicate with cable or wireless computer systems. There are also low cost and low immersion HMDs based on smartphones and cardboard parts.

Already in [45] the concept of "Customer Journey" is developed which illustrates all stages of a tourist's travel experience as a circular sequence. These stages consider that travelers use technology to: planning, booking, preparing, travel, arrive at the destination, and finally enjoy the destination. Considering these stages and the technologies that can be applied in each of them to explore experiential sensory marketing, this proposal seeks to apply in a first moment the development of technological solutions for the stages of planning, booking, arrival at the hotel, and enjoyment of hotel services [45].

Considering the "planning" stage, the digital technologies with which the traveler initially interacts are the Web sites and/or Web portals that offer tourist and hotel services [46]. Other factors to consider in "planning" are cultural characteristics, age ranges, and social conditions of travelers [47], in order to adequately outline the services to be offered, as mentioned by [48]. Therefore, our present proposal will consider all these factors to have a first contact with the traveler with immersive technologies appropriate not only from the technological point of view but also cultural context, which will allow us to develop concepts and solutions of profiling and recommendation.

The "arrival at destination" stage refers to the different services, products, events and other situations that may be in the context of the tourist and hotel service [44]. In this sense, immersive technology seeks to expand and improve the experience with these services, products and events, adding more information and allowing travelers to have a sensory experience. For [49], this requires not only immersive technology but also other hardware technologies that allow this information to be provided considering the context and location of services, products and events.

The review made it possible to establish that there are many research works that dealt with marketing actions, based on immersive technologies. However, in the opinion of the authors, it is important that in the specific case of experiential marketing, which considers five types of consumer experiences, the focus must be on aspects related to:

- Sensations, which appeal to the senses with the aim of creating sensory experiences, through sight, hearing, touch, taste and smell [1], which can be generated with display devices and natural NUI user interfaces, allowing to create experiences through different senses.

- Feelings, which appeal to the innermost feelings and emotions of consumers, with the aim of creating affective experiences, ranging from slightly positive moods linked to a brand to strong emotions of joy and pride, which can be experienced through the use of metaphors that awaken feelings and emotions based on visual devices and NUI.

- Thoughts, which appeal to the intellect in order to create cognitive experiences, that solve problems and attract consumers creatively; which can be implemented using metaphors and even avatars [50], defined as digital objects, which can represent people, animals or any object that represents information corresponding to the need and preferences of the consumer.

- Actions [10], which focus on creating customer experiences, related to physical aspects, behavioral patterns and lifestyles, as well as experiences that arise from the result of interacting with other people and scenarios, which in this case may be real, virtual world or even avatars.

- Relationships, which aim to offer the customer deep experiences in the social and cultural context, reflected in a brand, which goes beyond the feelings, sensations and actions of the customer as it can create connections between consumers and other users of the brand, which can be emulated, using simulation, transduction, navigation, among other resources of immersive technologies, to generate social relationships with real or simulated characters in virtual worlds.

Although all these types of experiential marketing have their own structure and principles, these are connected and interrelated with each other, the experiential marketing strategy being the incorporation of these 5 , for the creation of a holistic experience, which simultaneously integrates each of these five types of experiential marketing elements proposed by Schmitt [1], whose feasibility of realization is possible, using the hardware and software resources of the Emerging Immersive Technologies.

Finally, the personalization of experiences, based on information on user preferences and profiles would be possible through the classification and recommendation module proposed in the model, presented in Section VI.

\section{Software Architecture Proposal}

The tourism sector is key to the social and economic development of diverse communities and the fight against poverty. Traditionally, the development of the tourist sector has been directly related to the tourist infrastructure and to the products or tourist routes. Tourism infrastructure requires investments from governments for means of transportation and access, such as airports and highways. Private investments focus mainly on the hotel industry and means of final transportation to the tourist resource.

Currently, the hotel industry not only serves as operational support for the tourism sector, but is increasingly taken as a deciding factor for the realization of events and conventions of great magnitude for sporting, scientific, business and even governmental activities. In this sense, the hotel industry has 
become more sophisticated not only in its physical infrastructure, but also in the various services offered and the technology used in all its business processes and activities.

The technological evolution of the tourism and hotel sector began with information systems to improve business processes. Then the Internet revolution, the Web portals to show the hotel services, allowing the reservation and payment of such services. Already the development of technological concepts such as the Internet of Things (IoT), Virtual Reality and Immersion, has made the tourism sector and the hotel industry begin to take advantage of these technologies to better explore the marketing and advertising actions of the infrastructure and services they offer.

The combination of the concepts of experiential marketing and sensory marketing seeks to enrich the experience based on the direct communication of the marketing action to the senses of the consumer, to influence their decision and relationship with a product, service or brand. These marketing concepts, added to the immersive devices and technologies already described, allow the development of actions that generate added value and competitive advantage. In other words, the use of virtual reality lenses to show a hotel landscape or service, whose image is connected to sensors and actuators to enrich the sensory experience, which also considers information on consumer preferences and interests is a sum of concepts and technologies that are trends in technological development and marketing of the hotel industry with direct impact on the tourism sector.

Based on the above, a general and scalable software architecture is proposed that allows the development of VR systems for the scenarios of the tourism and hotel industry. In Fig. 4, the architecture organized in four related modules is presented. The first module at the top is called "Immersive Marketing Strategy", where the marketing strategy to be implemented is defined. This includes formally defining deadlines, content types and metrics to evaluate the expected results. The strategy leads to the virtual content generation module to determine what types of objects and virtual content should be created. For example, if the strategy seeks to promote a particular museum, this strategy defines what virtual objects should be created and what interactions are expected to be used.

The "virtual content generation" module provides the structure and links the tools that allow the generation of virtual objects. This includes the generation of 360 degree videos and simulations, which can be complemented with virtual objects that extend the information and interaction that is desired to be represented in the marketing strategy. This module is also responsible for the storage, simulation and testing of virtual content. The evaluation refers to the fact of verifying compliance with the strategy. The simulation already corresponds to the behavior of the solution with respect to different user profiles.

The "Virtual Content Recomendation" module represents the business logic and intelligence that effectively executes the established marketing strategy, since this module is responsible for building user or traveler profiles, considering parameters such as age, gender, country of origin, cultural or religious considerations, etc. In the same way, the recommendation algorithms determine according to the profile and the available immersion device which virtual objects and which interaction dynamics are presented to the consumer.

Finally, the "End User" module refers to the devices available to represent the marketing strategy. These devices and their characteristics determine the degree of immersion that can be achieved. For example, devices such as HMDs, Wired HMDs (Oculus Rift or HTC Vive) or Wireless HMDs (Samsung Gear VR) can allow a high degree of immersion. Already devices such as Google Cardboard represent Lowimmersion HMDs, which may allow less interaction, however, from a cost point of view, you may have a greater presence of these devices in the market. In addition, if there is no immersion device itself, the concepts of 360 Video / Web Browser AR / VR can be explored to interact with consumers. It is also important to note that the record of information regarding the interaction and immersion are recorded and used according to the evaluation metrics of the marketing strategy, to determine the effectiveness of it and rethink new actions to follow.

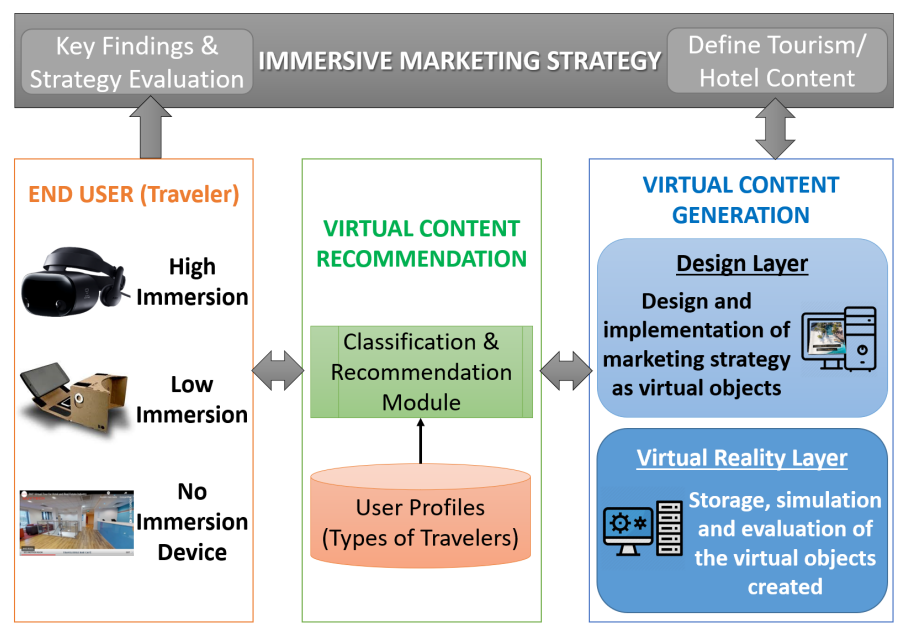

Fig. 4. System model for marketing, using immersive technologies

One of the most important contributions of this proposal is to incorporate a module of business logic and intelligence, whose responsibility is to execute the established marketing strategy, for which it builds profiles of the user or traveler, taking into consideration some specific parameters such as age group, gender, languages, country of origin, cultural and / or religious considerations, and so on. Using recommendation algorithms for this which will allow to determine according to the profile and the available immersion device, which virtual objects and which interaction dynamics will be presented to the user-consumer, and which will make possible the modeling of an immersive Marketing system with important attributes of adaptation to the user-consumer profile, a fact that will allow experiences with a high degree of customization. Likewise, it is also intended to contribute to the technological development and marketing of the hotel industry because technological innovation can have a significant impact on the results of business operations and specifically the tourism sector. 


\section{CONCLUSION}

- The state of the art of immersive Virtual Reality and its applications in the marketing of hotel services has been established, allowing us to know the enormous potential of this emerging technology which would make it possible to innovate the forms and methodologies for innovative marketing practices, since experiences close to reality can be considered, using metaphors that include multi-sensorial perceptions that arouse emotions and sensations in the client.

- A software architecture has been proposed oriented to the marketing of hotel services, based on immersive technologies incorporating recommendation algorithms, whose attributes of originality and innovation are unique.

- It is recommended that, in the development of the model proposal, the concepts of experiential and sensory marketing, as well as the immersive technology devices described, should come together. The use of Artificial Intelligence approaches will provide the model with some adaptive features, derived from user profiles, as well as the different environments that may have significance, using recommendation algorithms for this purpose

- It is recommended that the metaphors to be developed for the implementation of the proposed model should be carefully elaborated from the experiences of specialists in hotel and service marketing and Computer Science.

- It is recommended that, for the development of the proposed architecture, the conformation of a multidisciplinary work team should be contemplated, with diverse sources of experience, given the complexity of the investigation to be developed.

- It is important to use Artificial Intelligence approaches in order to provide the model with some adaptive characteristics, derived from the profiles of the users, as well as from the different environments that may have significance for it.

\section{ACKNOWLEDGMENT}

The authors would like to thank National University of San Agustín (UNSA), Technological University of Peru (UTP) and Pontifícia Universidade Católica (PUC-Rio- Brazil) for supporting this research.

\section{REFERENCES}

[1] B. Schmitt, "Experiential marketing," Journal of Marketing Management, vol. 15, no. 1-3, pp. 53-67, 1999.

[2] C. Grönroos, Service management and marketing: Managing the moments of truth in service competition. Jossey-Bass, 1990.

[3] I. Gallo, C. Townsend, and I. Alegre, "Experiential product framing and its influence on the creation of consumer reviews," Journal of Business Research, vol. 98, pp. 177-190, 2019.

[4] A. Simone and E. Sabbadin, "The new paradigm of the omnichannel retailing: Key drivers, new challenges and potential outcomes resulting from the adoption of an omnichannel aproach," International Journal of Business and Management, vol. 13, no. 1, 2018.
[5] E. Y. Yi-Hua and K. W. Chihkang, "Relationships among experiential marketing, experiential value, and customer satisfaction," Journal of Hospitality \& Tourism Research, vol. 32, no. 3, pp. 387-410, 2008.

[6] T. H. Pham and Y.-Y. Huang, "The impact of experiential marketing on customer's experiential value and satisfaction: An empirical study in vietnam hotel sector," Journal of Business Management \& Social Sciences Research (JBM\&SSR), vol. 4, no. 1, 2015.

[7] H. Hyunwoo, S. K. Yang, and J. C. Kyung, "Use of the smart store for persuasive marketing and immersive customer experiences: A case study of korean apparel enterprise," Mobile Information Systems, vol. 2017, 2017.

[8] L. Ortegón-Cortázar and A. G. Rodríguez, "Management of sensory marketing on the consumer's experiencer," Revista de Ciencias Sociales (Ve), vol. 12, no. 3, pp. 67-83, 2016.

[9] A. Parasuraman, V. A. Zeithaml, and L. L. Berry, "A conceptual model of service quality and its implications for future research," Journal of marketing, vol. 49, no. 4, pp. 41-50, 1985 .

[10] F. Balan, "Marketing experiencial," 2015.

[11] M. López-Rúa, "Persuasión a través del marketing sensorial y experiencial," Opción, vol. 31, no. 2, pp. 463-478, 2015.

[12] A. Krishna, "An integrative review of sensory marketing: Engaging the senses to affect perception, judgment and behavior," Journal of consumer psychology, vol. 22, no. 3, pp. 332-351, 2012.

[13] J. H. Gilmore and B. J. Pine, "Differentiating hospitality operations via experiences: Why selling services is not enough," Cornell Hotel and Restaurant Administration Quarterly, vol. 43, no. 3, pp. 87-96, 2002.

[14] M. K. Hui and J. E. Bateson, "Perceived control and the effects of crowding and consumer choice on the service experience," Journal of consumer research, vol. 18, no. 2, pp. 174-184, 1991.

[15] M. B. Holbrook and E. C. Hirschman, "The experiential aspects of consumption: Consumer fantasies, feelings, and fun," Journal of consumer research, vol. 9, no. 2, pp. 132-140, 1982.

[16] E. P. Goodman, "Stealth marketing and editorial integrity," TEX. l. rEV., vol. 85, p. 83, 2006.

[17] J. W. Donald, "The blood on the stacks arg: Immersive marketing meets library new student orientation," 2008.

[18] H. Skouteris, S. Edwards, H. Morris, R. Cox, L. Baur, L. Wolfenden, and T. T. Huang, "Early childhood education and health working in partnership: the critical role early childhood educators can play in childhood obesity prevention," Early Child Development and Care, vol. 187, no. 8, pp. 1239-1243, 2017.

[19] L. A. Alfaro, "Contribuições para a modelagem de um ambiente inteligente de educação baseado em realidade virtual," 1999.

[20] M.-S. Yoh, "The reality of virtual reality," in Proceedings Seventh International Conference on Virtual Systems and Multimedia, pp. 666674, IEEE, 2001.

[21] J. Psotka, "Immersive training systems: Virtual reality and education and training," Instructional science, vol. 23, no. 5-6, pp. 405-431, 1995.

[22] J. Psotka, "Educational games and virtual reality as disruptive technologies," 2013.

[23] J. R. Juang, W.-H. Hung, and S. C. Kang, "Simcrane 3d+: A crane simulator with kinesthetic and stereoscopic vision," Advanced Engineering Informatics, vol. 27, no. 4, pp. 506-518, 2013.

[24] R. Linares, "Exploration of scientific articles with virtual reality and natural language processing," 2017.

[25] B. S. Zohra, G. Fabrice, R. Paul, B. Julien, and P. Fabien, "An overview of interaction techniques and $3 \mathrm{~d}$ representations for data mining," Applications of Virtual Reality, p. 185, 2012.

[26] S. Dübel, M. Röhlig, H. Schumann, and M. Trapp, "2d and 3d presentation of spatial data: A systematic review," in 2014 IEEE VIS International Workshop on 3DVis (3DVis), pp. 11-18, IEEE, 2014.

[27] L. Alfaro, C. Portugal, J. Luna-Urquizo, and J. S. na, "Technical report: Development of image processing algorithms oriented to the recognition and analysis of forestation," tech. rep., Universidad Nacional de San Agustín, Arequipa - Perú, 2019.

[28] K. Wanarat and T. Nuanwan, "Using 3d visualisation to improve public participation in sustainable planning process: Experiences through the creation of koh mudsum plan, thailand," Procedia-Social and Behavioral Sciences, vol. 91, pp. 679-690, 2013. 
[29] N. Menck, X. Yang, C. Weidig, P. Winkes, C. Lauer, H. Hagen, B. Hamann, and J. Aurich, "Collaborative factory planning in virtual reality," Procedia CIRP, vol. 3, pp. 317-322, 2012.

[30] E. Lombardo, S. Agostinelli, and M. Metge, "Could an interactive and total immersive device with hmd improve memory and give the presence sensation?," 2013.

[31] L. Alfaro, R. Linares, and J. Herrera, "Scientific articles exploration system model based in immersive virtual reality and natural language processing techniques," INTERNATIONAL JOURNAL OF ADVANCED COMPUTER SCIENCE AND APPLICATIONS, vol. 9, no. 7, pp. 254263, 2018.

[32] D. Wigdor and D. Wixon, Brave NUI world: designing natural user interfaces for touch and gesture. Elsevier, 2011.

[33] N. Villaroman, D. Rowe, and B. Swan, "Teaching natural user interaction using openni and the microsoft kinect sensor," in Proceedings of the 2011 conference on Information technology education, pp. 227-232, ACM, 2011.

[34] G. Calle Condori, E. Castro-Gutierrez, and L. Alfaro Casas, "Virtual rehabilitation using sequential learning algorithms," INTERNATIONAL JOURNAL OF ADVANCED COMPUTER SCIENCE AND APPLICATIONS, vol. 9, no. 11, pp. 639-645, 2018.

[35] A. Câmara, "Natural user interfaces," in IFIP Conference on HumanComputer Interaction, pp. 1-1, Springer, 2011.

[36] S. Mann, Humanistic Intelligence as a Basis for Intelligent Image Processing. Wiley-IEEE Press, 2002.

[37] A.-P. Kontis and D. Lagos, "Factor framework for the evaluation of multichannel marketing mixes in $5^{*}$ city hotels," Procedia-Social and Behavioral Sciences, vol. 175, pp. 408-414, 2015.

[38] P. Phillips, S. Barnes, K. Zigan, and R. Schegg, "Understanding the impact of online reviews on hotel performance: an empirical analysis," Journal of Travel Research, vol. 56, no. 2, pp. 235-249, 2017.

[39] X. Tian, W. He, R. Tao, and V. Akula, "Mining online hotel reviews: a case study from hotels in china," 2016.

[40] Y. Zhao, X. Xu, and M. Wang, "Predicting overall customer satisfaction: Big data evidence from hotel online textual reviews," International
Journal of Hospitality Management, vol. 76 Part A, pp. 111-121, January 2019.

[41] A. Suh and J. Prophet, "The state of immersive technology research: A literature analysis," Computers in Human Behavior, vol. 86, pp. 77-90, 2018.

[42] M. G. Violante, E. Vezzetti, and P. Piazzolla, "How to design a virtual reality experience that impacts the consumer engagement: the case of the virtual supermarket," International Journal on Interactive Design and Manufacturing (IJIDeM), vol. 13 no. 1, pp. 243-262, September 2019.

[43] W. Winn, "A conceptual basis for educational applications of virtual reality," Technical Publication R-93-9, Human Interface Technology Laboratory of the Washington Technology Center, Seattle: University of Washington, 1993.

[44] J. Beck, M. Rainoldi, and R. Egger, "Virtual reality in tourism: a stateof-the-art review," Tourism Review, 2019.

[45] L. Neuburger, J. Beck, and R. Egger, "the "phygital" tourist experience: the use of augmented and virtual reality in destination marketing," in Tourism Planning and Destination Marketing, pp. 183-202, Emerald Publishing Limited, 2018.

[46] S. Moro, P. Rita, and C. Oliveira, "Factors influencing hotels' online prices," Journal of Hospitality Marketing \& Management, vol. 27, no. 4, pp. 443-464, 2018.

[47] T. H. Jung, H. Lee, N. Chung, and M. C. tom Dieck, "Cross-cultural differences in adopting mobile augmented reality at cultural heritage tourism sites," International Journal of Contemporary Hospitality Management, vol. 30, no. 3, pp. 1621-1645, 2018.

[48] V. Komianos, E. Kavvadia, and K. Oikonomou, "Cultural heritage recommendations and user navigation in large scale virtual environments.," IJCIStudies, vol. 4, no. 2, pp. 151-172, 2015.

[49] J. Scholz and A. N. Smith, "Augmented reality: Designing immersive experiences that maximize consumer engagement," Business Horizons, vol. 59, no. 2, pp. 149-161, 2016.

[50] R. Linares, J. Herrera, and L. Alfaro, "Aliciavr: Exploration of scientific articles in an immersive virtual environment with natural user interfaces," in 2016 IEEE Ecuador Technical Chapters Meeting (ETCM), pp. 1-6, IEEE, 2016. 